\title{
The motive ideas behind three industrialization processes
}

Norberto González*

In its most orthodox version, neoclassical economic theory has occupied a leading place in Latin American economic policy discussions in recent years. According to this doctrine, the market mechanisms -if allowed to operate in complete freedom- allocate production resources in the most efficient manner possible. Any interference by State policy with this allocation will lead to loss of efficiency and a reduction in the growth rate of the economy compared with the optimum level that could be obtained through the free play of the market forces. The virtues of the main body of this economic theory for interpreting reality have been proved over more than two centuries. But this does not justify overlooking the serious limitations affecting the operation of the market or the differences observed in that operation in the different stages of countries' development. In the historical period in which they began their industrialization processes, the countries which are now developed applied policies of active State participation in combination with the free functioning of the market, and formulated theories which gave technical backing to those policies.

Although these facts have been studied and are well known in academic circles, very little reference is made to them in economic policy discussion in our region. I therefore propose in this essay to recall the ideas which

* Former Executive Secretary of ECLAC. The basic material for this article was prepared while the author was collaborating with the Institute of Economics of the University of the Oriental Republic of Uruguay, when the Institute was under the direction of Octavio Rodríguez. guided the evolution of two important economic policies: those of the United States and of Germany. Due to lack of space, I shall not deal with the case of Japan, which also applied policies in the last century which combined State and private action. The first two cases will be used in this essay as the background for analysing the ideas of Prebisch and ECLAC applied to the case of Latin America.

\section{The case of the United States. Alexander Hamilton}

These ideas on the industrialization of the United States were set forth by Alexander Hamilton in 1791 (see Hamilton, 1934). This author questioned the validity of the objections against policies for the promotion of manufactures and the assertion that -without government aid- industry would grow as quickly as the natural state of things and the interests of the community required. According to Hamilton, this assertion is not always true. Inertia and a tendency to imitate are reflected in fears about failing in new ventures, the obstacles inseparable from first experiments in competing with nations which have already perfected a particular branch of industry, and the artificial incentives with which foreign countries support their citizens (Hamilton, 1934).

Hamilton goes on to say that "Experience teaches ... that the simplest and most obvious improvements, in the most ordinary occupations, are adopted with hesitation, reluctance and by slow gradations. The 
spontaneous transition to new pursuits ... may be expected to be attended with proportionably greater difficulty. ... these changes would be likely to be more tardy than might consist with the interest either of individuals or of the Society ... and ... in many cases they would not happen. ... To produce the desireable changes, as early as may be expedient, may therefore require the incitement and patronage of government. The apprehension of failing in new attempts is perhaps a more serious impediment ... it is essential that [those embarking on such new ventures] should be made to see ... the prospect of such a degree of countenance and support from government, as may be capable of overcoming the obstacles, inseperable from first experiments". "The superiority antecedently enjoyed by nations, who have preoccupied and perfected a branch of industry, constitutes a more formidable obstacle ... to the introduction of the same branch into a country, in which it did not before exist. To maintain between the recent establishments of one country and the long matured establishments of another country, a competition upon equal terms, both as to quality and price, is in most cases impracticable ... without the extraordinary aid and protection of government". Thus, government aid for infant industry in a new country may be essential in order to offset inequalities of competition in the initial period.

Thanks to the reports by Hamilton and by some of his followers, such as H.B. Carey, who advocated these ideas in 1865 , these concepts spread and strongly influenced the trade and industrial policy applied by the United States during its industrialization process (see Mill, 1987).

\section{The case of Germany. Frederick List}

The industrialization policy for Germany was set forth in similar, albeit broader, terms by Frederick List in the nineteenth century (List, 1856). List claims that, during the initial period of development of an industry in a new country, government aid for the infant industry may be essential in order to equalize the conditions of competition. He maintains "The protective system is the only means by which nations less advanced can be raised to the level of that nation which enjoys a supremacy in manufacturing industry. A monopoly not conferred by nature, but seized by being first on the ground; the protective system, regarded from this point of view, will be most effective promoter of universal association among nations, and consequently free trade" (List, 1856, p. 201). Although he recognizes that in the beginning customs protection increases the price of manufactures, he maintains "that in course of time, in a nation capable of large industrial development, such articles can be produced at a cheaper rate than they can be imported from abroad" (List, 1856, p. 224). The initial sacrifice "is amply compensated by the acquisition of a productive power, which ensures not only a larger product of wealth in future, but also a greater industrial independence" (List, 1856, p. 224).

Citing Say, he accepts that the State may protect national industry provided that within a few years that industry can survive unaided, just like "... a shoemaker's apprentice, to whom a few years' teaching and support is accorded that he many learn his trade to live without further help from his parents" (List, 1856, p. 262).

List's proposals go further than those of Hamilton. $\mathrm{He}$ not only refers to the greater independence in industrial matters that this policy gives to a country, but also notes that the progress of industry in a predominantly agricultural country has more general consequences for development. It stimulates urban growth and has a positive influence on social and political development, on intellectual and cultural progress, and on creative capacity. Industrial development makes possible increased productivity throughout the economy and development of the means of transport.

He highlights the interdependence between industrial and agricultural development, noting that industrial development stimulates and diversifies demand for agricultural products (List, 1856, p. 295). During the process of industrial development, each new industry supports the development of others (List, 1856, p. 377). This assertion brings out the intersectoral and not merely individual nature of industrial policies.

List hints at the structural nature of the economic development process when he asserts that the development of manufacturing is only attained slowly and gradually. It takes a long time to improve equipment, production processes and distribution systems. It is easier to perfect and expand an existing enterprise than to start up a new one. Old industries, which have been developed over generations, can be promoted more easily than new ones. It is more difficult to make an enterprise progress when there have been few or no such enterprises in the country in the past, since in new enterprises the managers and workers have to be trained or brought in from outside, and the prospects are not promising enough to give capitalists the degree of confidence needed to ensure their participation. Over generations, it is possible to improve 
the price, quality and quantity of the production (List, 1856, pp. 373-374).

These ideas open up a broader horizon than that of the industrial sector itself and are forerunners of later, technical proposals. The manufactures of a newly industrialized country, List says, "can be compared with a youth struggling with a fully grown man. The manufactures of the chief industrial and commercial power possess a thousand advantages over those of new or as yet not fully mature nations. They have ... skilful and experienced workmen in great numbers and at low wages, men of special skills and experience in management, ... financial institutions, ... transport facilities, ... efficient storage and distribution systems, ... a domestic market which provides them with support for conquering outside markets". In those conditions, it would be useless for a new country to trust exclusively in the natural evolution of the economy to develop an industry in free competition with the most highly developed nations (List, 1856, pp. 378-379). List, like Hamilton and other classical authors, considered that there must be limits on policies for the promotion and protection of industry: protection and support should not have excessive levels, should be kept in being only for a reasonable length of time, and should be applied to activities in which the country had the possibility of being competitive (List, 1856, pp. 390-393). Customs duties should be considered and applied only for the benefit of sectors which offered basic advantages for the country.

\section{More general cases: John Stuart Mill and neoclassical theory}

Mill acknowledged the legitimacy of industrialization policy by incorporating the infant industry argument into classical theory. His ideas (Mill, 1987) were based on the more pragmatic and limited version of Hamilton rather than that of List. ${ }^{1}$

Pages 922 and 923 of Mill (1987) contain the following well-known paragraph: "The only case in which, on mere principles of political economy, protecting duties can be defensible, is when they are imposed temporarily (especially in a young and rising nation) in hopes of naturalizing a foreign industry, in

\footnotetext{
${ }^{1}$ List showed himself to be a capable and far-sighted economist, but he advocated nationalist views which shocked other authors of his time, as described in the essay by G. A. Matile, who edited List's works.
}

itself perfectly suitable to the circumstances of the country. The superiority of one country over another in a branch of production, often arises only from having begun it sooner. There may be no inherent advantage on one part, or disadvantage on the other, but only a present superiority of acquired skill and experience. A country which has this skill and experience yet to acquire, may in other respects be better adapted to the production than those which were earlier in the field: and besides, it is a just remark of Mr. Rae, that nothing has a greater tendency to promote improvements in any branch of production, than its trial under a new set of conditions. But it cannot be expected that individuals should, at their own risk, or rather to their certain loss, introduce a new manufacture, and bear the burthen of carrying it on until the producers have been educated up to the level of those with whom the processes are traditional. A protecting duty, continued for a reasonable time, might sometimes be the least inconvenient mode in which the nation can tax itself for the support of such an experiment. But it is essential that the protection should be confined to cases in which there is good ground of assurance that the industry which it fosters will after a time be able to dispense with it" (Mill, 1987, pp. 922-923).

Neoclassical theory has refined the infant industry argument and clarified its validity. But at the same time it has helped to limit its application. It analyses the case of external economies, where the company making the investment does not capture all the resulting benefits, part of which may be diverted to other firms through the transfer of skilled labour, or through firms which supply the company which made the investment with non-tradeable goods, or through acquisition of its products (Corden, 1974, pp. 256-257). In these cases, it might be necessary to compensate that company for the benefits of the investment that it does not capture.

Neoclassical theory also takes account of the case where there are reciprocal external economies and none of the companies involved captures the total result of the investment (Corden, 1974, p. 260).

In the neoclassical school, there is some skepticism about the application of industrialization policies. Although the validity of the infant industry argument is usually accepted, it is considered that such policies are not the best alternative, but rather second- or thirdbest options. It is maintained that rather than applying active industrial policies it would be more efficient to improve the information available to entrepreneurs for taking their decisions or to try to improve the capital markets, leaving it to the market, free of all outside 
interference, to allocate resources. This would give industrial policies less leeway than was allowed to them by the classical authors who influenced the industrialization processes of the United States and Germany.

Two main positions may be observed in the recent application of neoclassical theory to economic policy for the developing world in general and Latin America in particular:

On the one hand, there is the more orthodox point of view, which gives public policies a much-reduced role and leaves the allocation of production resources to the unfettered functioning of the market. It attaches decisive importance to maintaining fiscal and monetary balance, and advocates the reduction of the public sector to a minimum, the privatization of State activities, and deregulation. The supporters of this approach are openly hostile to active production development policies and attempts to change the economic structure, such as promotion of industry, policies designed to support technological progress, and trade policies based on protection and export promotion.

During the Reagan administration in the United States, this line of thinking, promoted by a supply-side economy, was very much in vogue. Even after the end of that administration, however, it has continued to enjoy strong support, especially among conservative groups, Latin America's private international creditors, and domestic sectors in Latin American countries associated with those financial circles. In the words of Feinberg (1990): "On one side are those who favor the restrictive Reaganite model: provide for national defense, set the appropriate macro conditions, and walk away".

On the other hand, there is also a less rigid neoclassical position which accepts some degree of active policies to promote industrial and technological development and support new exports. This position sets quite strict limits for such policies, however, both as regards the instruments used and the intensity with which they are applied in particular sectors, and also the length of time they are applied to each sector of production. Generally, though not always, it accepts one exception to the ideal of free trade, namely, infant industries, which may warrant substantial protection, but only on a temporary basis (Williamson, 1990, p. 15).

In another paragraph, Williamson refers to his own position on subsidies: “... for my taste, the hostility toward subsidies tends to be too general. I fully sympathize with the hostility toward indiscriminate subsidies, but I also believe that there are circumstances in which carefully targeted subsidies can be a useful instrument ... for improving either resource allocation or income distribution" (Williamson, 1990, p. 12). Stiglitz (1998) also takes a broader view on economic policies which can be applied without distorting the operation of the markets.

\section{The case of Latin American industrialization: the Prebisch and ECLAC approach}

Prebisch and ECLAC also opted for an approach involving deliberate industrialization, with State participation, in support of the private sector. They took a broad-based approach which, although centering mainly on economic matters in its operational aspects, also covered social issues, especially for the interpretation of the process. Changes in economic structures, industrialization, agricultural development, international economic relations, saving and investment, employment and income distribution were other issues analysed extensively and in depth.

Prebisch had been brought up in the classical economic tradition, and in the first years of his professional life he was an orthodox economist. As he himself said: "I believed in the universal validity of the theories developed in the centres" (González and Pollock, 1991). As a young Under-Secretary of Finance of his country, in the early 1930s, he recommended the government to apply orthodox policies in monetary, fiscal, trade and exchange matters. Soon, however, his ideas began to change, as a result of his experience in government which began in that period and continued later in the Central Bank of the Argentine Republic. There were two main aspects of that change: i) he came to the conclusion that, in the light of the world crisis, the Argentine economy would not recover using orthodox policies, in view of the ongoing deterioration in exports, which contrasted with the tendency towards strong growth in import needs; and ii) the failure of the 1933 World Economic Conference and the fact that Keynes's ideas on international cooperation found almost no acceptance among the European countries convinced him that Argentina could not hope for a solution through the reactivation of world demand. The tough bilateral negotiations for the Roca-Runciman treaty with Great Britain clearly revealed to him the limits imposed by a high degree of dependence on the export of primary commodities to a few foreign markets (González and Pollock, 1991).

As a result of this experience, he became convinced that it was essential to change the country's structure 
of production and of exports through industrialization, and that to secure this objective it was necessary to combine the play of the market forces with State action designed to promote and guide private sector action. Prebisch had become clearly aware of the profound repercussions on developing countries caused by crises originating in the developed countries, and knew that little could be done to avoid such crises.

His experience in Argentina served as the ground in which Prebisch's ideas initially germinated, to be subsequently developed in ECLAC and later still in the United Nations Conference on Trade and Development (UNCTAD).

According to Prebisch, the developing countries -which were on the periphery- specialized in the production of primary commodities. This resulted in an asymmetrical structure of their trade and financial relations with the developed countries. They exported low-technology goods and imported high-technology ones. Their exports were produced by unskilled labour, with a weak level of trade union organization, and the demand for them was marked by low income elasticity. As a result, this demand grew only sluggishly, and the exports provided low and unstable wages and profit margins. Their imports, in contrast, contained skilled, highly unionized labour, and their income elasticity was high, meaning higher wages and profit margins and faster growth for the supplier countries.

This asymmetrical structure of the external relations of the developing countries limited their growth potential, while their structural economic and social heterogeneity was reflected in unequal income distribution whose most evident -though not its onlyfeatures were poverty and marginality.

The cornerstone of the recommendations he made on the basis of this diagnosis was the industrialization process, which would make it possible to change the domestic production structure and external relations. This process could not be induced fast enough solely through the unaided effect of the free market forces, but required active public protection and promotion policies in the fields of trade, taxation and credit.

This policy varied with time, changing its emphasis according to the variations in the international economic situation and the development of industry in the region. In the post-war period, the markets of the developed countries were closed by high protectionist barriers, so that policy was aimed preferentially at the domestic market, through import substitution. Prebisch and ECLAC, however, considered that in view of the small size of that market import substitution meant inefficiency, so they recommended integration among the Latin American countries in order to create bigger markets and greater competition, and ECLAC gave strong support to the Central American integration process, the Latin American Free Trade Association (LAFTA)/ Latin American Integration Association (ALADI) and the Andean Group. From the 1960s on, as the markets of the developed countries showed themselves to be somewhat more receptive to Latin American manufactures, ECLAC maintained a programme to provide technical support for policies to promote the export of manufactures.

There was also an ongoing evolution of the priority production sectors in the industrialization process, from sectors producing non-durable and durable consumer goods at the start, to intermediate and capital goods with greater requirements in terms of investment and technology later on. The production of consumer goods created the subsequent demand for intermediate and capital goods: a form of evolution endorsed by ECLAC studies on industrial sectors and policies.

In order for progress to be made in policies to support the production of manufactures, two complementary elements were required:

i) A technology policy whereby the State provided support for the creative adaptation of outside technology to the special conditions of the Latin American countries and helped to speed up the innovation process. This increased efficiency, reduced costs, and improved the quality of the goods produced, so that they were better adapted to the demand on external markets. A project was carried out in collaboration with the InterAmerican Development Bank (IDB) in this field.

ii) As well as the efforts of the developing countries themselves, the export of manufactures required the active collaboration of the developed countries, which should open up their markets. One of the main objectives of Prebisch's work at UNCTAD -ably seconded by ECLAC in the Latin American area- was the creation of a generalized system of preferences, with unilateral opening of the markets of the developed countries in favour of the developing countries, through specific lists of goods that the developing countries were interested in exporting.

Although industrialization was the hub of the policies advocated by Prebisch and ECLAC, its success would call for the simultaneous application of other policies too.

Thus, an international cooperation policy was required, in order to secure a substantial increase in the 
flow of medium- and long-term capital from the developed countries to the region. Domestic saving capable of being turned into foreign exchange was not sufficient to finance an acceptable growth rate, as was reflected in the saving and trade deficits. International cooperation was possible, thanks to the political climate prevailing at the end of World War II and the political competition between the capitalist developed countries and the socialist countries. The World Bank, which was set up soon after the war, was complemented with the establishment of the Inter-American Development Bank (IDB), in whose creation ECLAC played a leading role. Mechanisms were also established in the countries of the region to ensure that medium- and long-term capital of public origin was invested efficiently, with the highest possible yield in terms of its contribution to economic development and employment and with guaranteed payment capacity. These mechanisms operated efficaciously until the abundance of international funds created by the oil price rises from the 1970s on and the surplus savings being accumulated by the developed countries turned the shortage of international funds into a glut. This led to the slackening of the discipline which had prevailed up to then and encouraged unproductive or imprudent use of the funds, culminating in the 1980s in the Latin American external debt crisis.

It was also necessary to pay special attention to two interrelated social issues: income distribution and employment. Income distribution was a matter of growing concern for Prebisch and ECLAC from the 1950s on, unlike conventional theory, which paid little attention to this issue because it based its ideas on the principle that, in an equilibrium situation, redistribution could not improve one person's income without adversely affecting that of another person. ECLAC, however, considered that Latin American industrialization received substantial support from the domestic market, so that better income distribution -quite apart from its importance for equitywas of great economic significance because it promoted the broadening of the domestic market and the incorporation into it of a high proportion of the previously marginalized population. With regard to employment -the other aspect of marginality-specific objectives and forms of development were proposed which would make it possible to progress towards the solution of structural unemployment and underemployment within a reasonable length of time.

Another two methodological aspects were given a great deal of attention by ECLAC: the investment projects manual, and planning - two technical instruments which were placed at the disposition of countries in order to help them to ensure the most efficient possible use of their resources. In the projects manual, a project preparation technique was described which increased projects' contributions to development and employment to the maximum, thus offering a means of relieving external constraints. This technique was very useful for submitting projects to financing bodies and evaluating their effects from the point of view of the entrepreneur and society. Planning, for its part, was put forward as a means for designing medium- and long-term policies and following up their implementation in order to ensure, as far as possible, that the structural changes pursued were effectively obtained. It aimed to secure coherence of the objectives proposed in development policies and compatibility of those policies with the restricted resources available, especially savings and foreign exchange. ECLAC therefore made the institutionalization of development planning one of the main objectives.

(Original: Spanish)

\section{Bibliography}

Corden, W.M. (1974): Trade Policy and Economic Welfare, Oxford, United Kingdom, Clarendon Press.

Feinberg, R.E. (1990): Comments, in J. Williamson (ed.), Latin American Adjustment. How Much has Happened?, Washington, D.C., Institute for International Economics.

González, N. and D. Pollock (1991): Del ortodoxo al conservador ilustrado. Raúl Prebisch en la Argentina, 1923-1943, Desarrollo económico, Revista de ciencias sociales, vol. 30, No. 120, Buenos Aires, Instituto de Desarrollo Económico y Social.

Hamilton, A. (1934): Secretary of the Treasury. Report on manufactures. Communicated to the House of Representatives, December 5, 1791, in S. McKee, Jr. (ed.), Papers on Public Credit, Commerce and Finance, New York, Columbia University Press.
List, F. (1856): National System of Political Economy, Philadelphia, J.B. Lippincott \& Co.

Mill, J.S. (1987): Principles of Political Economy, Fairfield, New Jersey, Augustus M. Kelley Publishers.

Stiglitz, J.E. (1998): Más instrumentos y metas más amplias para el desarrollo. Hacia el consenso post-Washington, Desarrollo económico. Revista de ciencias sociales, vol. 38, No. 151, Buenos Aires, Instituto de Desarrollo Económico y Social.

Williamson, J. (1990): What Washington means by policy reform, in J. Williamson (ed.), Latin American Adjustment. How Much has Happened?, Washington, D.C., Institute for International Economics. 